\title{
PHYTOCHEMICALS AS POTENTIAL ANTIVIRAL AGENTS IN SARS-COV-2 THERAPY: AN UPDATE
}

\author{
Nerilson M. Limaa,*, Teresinha de Jesus A. S. Andrade ${ }^{\mathrm{b}}$, Kojo S. Acquah', Marcone A. L. de Oliveiraa,*, ${ }^{\mathrm{a}, \text { Kellyane F. Gois }}{ }^{\mathrm{d}}$ \\ and Lis Cardoso M. Medeiros ${ }^{\mathrm{d}}$ \\ ${ }^{a}$ Universidade Federal de Juiz de Fora, Departamento de Química, Juiz de Fora - MG, Brasil \\ bNúcleo de Investigação Aplicado às Ciências, Instituto Federal de Educação, Ciência e Tecnologia do Maranhão, Presidente \\ Dutra - MA, Brasil \\ 'Department of Chemistry, University of Cape Town, South Africa \\ ${ }^{\mathrm{d} C e n t r o ~ d e ~ E s t u d o s, ~ P e s q u i s a ~ e ~ E x t e n s a ̃ o ~ e m ~ E d u c a c ̧ a ̃ o ~ P e r m a n e n t e ~ p a r a ~ o ~ S U S, ~ U n i v e r s i d a d e ~ F e d e r a l ~ d o ~ P i a u i ́, ~ T e r e s i n a ~-~ P I, ~ B r a s i l ~}$
}

Recebido em 08/10/2020; aceito em 27/01/2021; publicado na web em 18/02/2021

\begin{abstract}
In December 2019, the World Health Organization officially announced the discovery and fast spread of the new coronavirus disease (COVID-19), which is caused by the SARS-CoV-2 (Severe Acute Respiratory Syndrome Coronavirus 2), discovered in Wuhan, China. Since the beginning of the pandemic, there has been a global search for the discovery of antiviral candidates capable of treating the infection caused by SARS-CoV-2. However, none of them has shown proved efficacy and low toxicity for an effective dose. In view of this, research with plants based in natural products has been highlighted by the low toxicity of its metabolites and reduced side effects, since plants have been used for millennia in the treatment of various diseases. In this review, we highlight some plant species and plant metabolites belonging to the structural class of phenolic, alkaloids and terpenes with promising antiviral potential against coronavirus that could be explored as potential candidates for drug prototypes in the treatment of COVID-19.
\end{abstract}

Keywords SARS-CoV-2; COVID-19; phytotherapy; phytochemicals; antiviral.

\section{INTRODUCTION}

The emergence of the novel coronavirus disease, named COVID-19, in December 2019, has been one of the world's greatest epidemiological challenges of the century. The World Health Organization (WHO) therefore declared this disease a pandemic and a global health emergency in January 2020. COVID-19 is considered the most serious pandemic since the Spanish influenza (H1N1) pandemic in 1918. ${ }^{1,2}$

COVID-19 is caused by the novel coronavirus, which was officially named as SARS-CoV-2 (Severe Acute Respiratory Syndrome Coronavirus 2) by the WHO. The origin of SARSCoV-2 has been traced to a food market in Wuhan, China. To date (mid-January 2021), WHO has confirmed more than 90 million cases and more than 1.9 million deaths in 223 Countries, areas or territories. $^{3}$

The SARS-CoV-2 is similar to the Severe Acute Respiratory syndrome (SARS-CoV) and the Middle Eastern Respiratory Syndrome Coronavirus (MERS-CoV). ${ }^{4}$ In addition, recent studies have speculated that rhinolophid bats harbor viruses closely related to COVID-19. ${ }^{5}$ Coronaviruses (CoVs) have a genome characterized by a high frequency of mutations and recombination, acquiring a high potential to alternate hosts and pathogenicity. ${ }^{6}$

The syndrome incubation period is generally between 7 to 14 days, however, cases of up to 24 days have been reported. ${ }^{7}$ Some common symptoms that have been specifically linked to COVID-19 include fever, shortness of breath, tiredness and a dry cough that gets more severe over time. ${ }^{8}$ However, in severe cases, the disease can cause respiratory failure, shock and sepsis, which may even lead to death. ${ }^{9}$

Efforts are being made globally to find measures to control COVID-19 pandemic and this includes the search for effective drugs and/or vaccines. Given that the development of a new drug may take more than a decade, scientists are employing drug repurposing strategy, which hundreds of drugs that are already used to treat other infections like HIV, Malaria and Ebola are being tested against COVID-19.

Several controlled and randomized clinical studies of repurposed, repositioned and rescued drugs are being carried out. However, none of them have yet shown proved efficacy and low toxicity for an effective dose. Currently, there are no specific treatments approved for COVID-19. In view of this, research on natural phytochemical products, has been highlighted by the low toxicity of its metabolites and reduced side effects, since plants have been used for millennia in the treatment of various diseases, both for their effectiveness and economic accessibility. Additionally, natural products derived from plants can act as immunomodulation, eliminating the inflammatory reaction responsible for the great morbidity and mortality caused by the infection by the SARS-CoV-2 virus. ${ }^{10}$

Therefore, this update describes some phytochemical and medicinal plant species with promising antiviral potential against coronavirus that can be explored as potential candidates for drug prototypes in the treatment of COVID-19.

\section{METHODOLOGY}

Data on phytochemicals and medicinal plant species were updated daily and obtained using different search engine databases, including Web of Science, PubMed, Science direct, World Health Organization website, Google Scholar and Scopus. All articles and information collected and used for this review were either published or accepted for publication in Portuguese and English language journals. All articles published in the specialized literature in the last decades were analyzed, considering that this work summarizes natural products with antiviral potential against other coronavirus strains such as SARS-CoV and MERS-CoV.

*e-mail: nerilsonmarques@gmail.com; marcone.oliveira@ufjf.edu.br 


\section{SCREENING OF MEDICINAL PLANTS AND PHYTOCHEMICALS WITH POTENTIAL TO INHIBIT THE NOVEL CORONAVIRUS SARS-CoV-2}

Coronavirus $(\mathrm{CoV})$ is a positive sense single-stranded RNA (ssRNA) virus that belongs to the Coronaviridae family. Viral species belonging to this family cause infection of the upper respiratory and gastrointestinal tracts in mammals and birds, and in humans, mainly cause a common cold, but complications can occur, including pneumonia. The best known human coronaviruses $(\mathrm{HCoV})$ are the most widely known severe acute respiratory syndrome coronavirus (SARS-CoV) that caused a global threat with high mortality in 2003, the Middle East respiratory syndrome coronavirus (MERS-CoV) that is associated with high lethality, and the Severe Acute Respiratory Syndrome Coronavirus 2 (SARS-CoV-2), which is responsible for the current COVID-19 pandemic. ${ }^{11-13}$

The novel coronavirus, SARS-CoV-2, is classified in the $\beta$-line from Betacoronaviruses, which includes the SARS-CoV and MERS-CoV viruses, whose particles have rounded or oval structures with an approximate diameter of 60-140 nm. ${ }^{14}$ The infection process begins with the entrance of the virus into the host cell and the subsequent production of the viral polyprotein that needs to be cleaved into effector proteins through the host cell machinery. The main coronaviral protease (3CLpro) and papain-like protease (PLpro) enzymes are the viral proteases responsible for the cleavage. ${ }^{15}$ Genomic approaches indicate that SARS-CoV-2 has a genome ranging from $29.8 \mathrm{~kb}$ to $29.9 \mathrm{~kb}$ and share $96 \%$ similarity in the coronavirus genome found in bats and $79.6 \%$ sequence identity to SARS-CoV. ${ }^{16}$

The COVID-19 infection caused by the SARS-CoV-2 represents one of the greatest epidemiological challenges of the century, and to date there are no effective antiviral agents for many strains of coronavirus, including SARS-CoV-2. Considering that there are no treatment options available for the treatment of COVID-19 and the development of a medicine can take decades, the drug repositioning strategy has been used (Figure 1). The drug repositioning strategy is a process of identifying new uses for approved or research drugs and it is considered a very effective tool for drug discovery, as it involves less time and cost to find a therapeutic agent compared to the new drug discovery process. ${ }^{17}$

Concerning the drug repositioning strategy, numerous studies are currently being conducted through in vitro and clinical tests using drugs already used in a clinical setting for other pathologies. Many antiviral, antibacterial, antifungal and antiparasitic drugs have demonstrated a potential effect against COVID-19. Among the therapeutic alternatives for COVID-19 that have shown promising are the antivirals Lopinavir, Ritonavir, Remdesivir and Favipiravir, which are drugs that act in the deactivation of the viral particles that appear after the viral replication process and prevent the virus from binding to the receptor cell and inhibition processes related to its replication. ${ }^{18-20}$ Other prominent drugs that have led to important discussion about their use are the antimalarial and antiprotozoal Chloroquine and Hydroxychloroquine, which are aminoquinolines with known anti-inflammatory ${ }^{21,22}$ and antimalarial properties. ${ }^{23,24}$ The antibiotic azithromycin has emerged as a promising alternative therapy, since its use in addition to other drugs has been applied in clinical therapy to treat viral infections and to prevent severe respiratory tract infections in patients with these infections..$^{25,26}$ The antiprotozoal nitazoxanide also stood out in these studies because it is also known to enhance the production of interferon-alpha and interferon-beta and has recognized antiviral activity in vitro against coronavirus strains including MERS-CoV. ${ }^{27}$ We also highlight the drug Nafamostat, a serine protease inhibitor that acts as an anticoagulant and showed excellent inhibition potential for MERS-CoV and SARS-CoV-2 coronaviruses, preventing membrane fusion. ${ }^{28}$

However, non-pharmacological approaches have proved to be the most efficient strategy to date and has shown potential cure since the effectiveness of these drugs as anti-SARS-CoV-2 and their mechanisms of action, pharmacokinetics, dosage and safety do not guarantee their use in COVID-19 therapy. In this context, nature is an inexhaustible source of molecules with chemical and biological activity potentials for application in human health, providing molecular models for the development of clinically useful drugs in the treatment of several infections. The compounds derived from natural products present in the various organisms (plants, microorganisms, seaweed, animals, etc.) provide a potential wealth of antiviral agents that can be used in therapy against COVID-19. Thus, we review the literature on natural products from plants against different human and animal coronaviruses and highlight the secondary metabolites (phenolic compounds, terpenes and alkaloids) and medicinal plants in their various pharmaceutical forms that are used in traditional Chinese medicine that show the greatest potential for the development of drugs to combat and control the novel coronavirus (Figure 1).

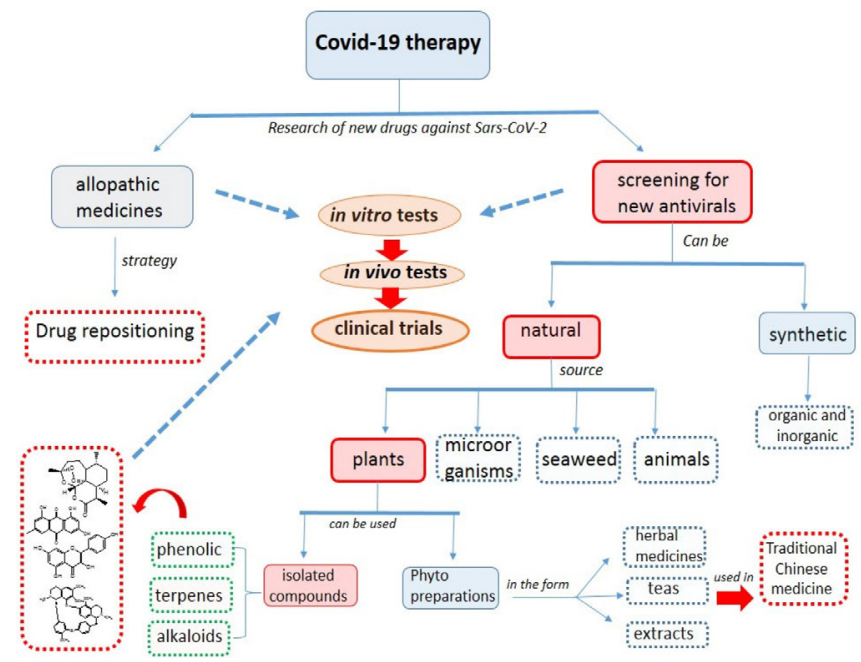

Figure 1. Strategies and steps for the development of new candidates for anti-SARS-CoV-2 drugs

The epidemiology, transmission, prevention and pathology of COVID-19 are still being elucidated, since it is a new disease. Preventive care such as hygienic habits, use of personal protective equipment and avoidance of physical contact with infected patients is very necessary. Since COVID-19 has no cure, symptoms of infected patients receive the best possible clinical treatment through supportive therapy such as mechanical ventilation, administration of antimicrobials and monitoring of clinical progression. ${ }^{29}$ However, invasive mechanical ventilation can trigger other physiological effects including venous thromboembolism, pressure or stress ulcers and catheter-related blood infections. ${ }^{29}$ Some natural compounds, for example the terpene celastrol (1), have been shown to improve ventilator-induced lung injury in animals. ${ }^{30}$ Thus, phytotherapy can emerge as an important alternative measure to treat the pathology caused by COVID-19. Some studies based on traditional Chinese medicine have suggested some therapies to treat the clinical symptoms of COVID-19 disease and this is based on antiviral constituents present in the species studied. ${ }^{31}$

The SARS-CoV coronavirus caused an acute infection epidemic in China at the beginning of the century. Many plant based secondary metabolites that showed activity against this strain could produce similar activity against this novel coronavirus (SARS-CoV-2). Given that shorter hospitalizations, and reduced side effects were observed 
in patients infected with SARS-CoV treated with traditional Chinese medicine, this therapy encourages doctors to assist this type of therapy in the treatment of COVID-19. ${ }^{32}$

Due to the difficulty of carrying out experiments and obtaining results from preclinical and clinical studies in a short period to treat COVID-19, many studies are being conducted in silico. For example, Zhang et al. ${ }^{33}$ studied the effectiveness of several products of traditional medicine in treating viral infection, and subsequently evaluated the ability of the chemical constituents present in these materials of natural origin to interact and attack viral enzymes of the novel coronavirus. These medicinal herbs selected in this pharmacological screening were chosen due to their folkloric medicinal use in treating lung infections and the proven antimicrobial activity of the chemical components of these herbs.

These in silico computational studies have a crucial role in the development of new prototypes of drugs and auxiliary therapies, since the compounds that show a positive response in theoretical calculations are subsequently explored further in cell culture experiments and preclinical animal studies. On the other hand, one should consider the possibility that the parameters used in in vitro tests may not be reproducible and reached in in vivo experiments after therapeutic administration.

In addition, many studies have been developed to identify the mechanisms of antiviral action of these metabolites and, thus, to develop more effective and less toxic drugs. Therefore, it is important to know how these anti-infectious agents interact with the viral life cycle, such as viral entry, replication, assembly and release and the targeting of specific virus-host interactions. ${ }^{34}$

However, medicinal herbs and their phytochemicals that show curative potential are not always able to directly inhibit viral replication and kill the virus, some of which are used only to relieve symptoms and clinical manifestations caused by infection, as well as improve immunity of the patient and act in the recovery of organ function. ${ }^{35}$

Based on previous studies carried out with SARS-CoV and MERS-CoV strains, many compounds and medicinal herbs have stood out as potential candidates in Covid-19 therapy, as result of the viral genomic similarities and the clinical manifestations presented. The plant Artemisia annua, for example, has been studied as a potential source of antiviral constituents, since it has shown antiviral activity against hepatitis B virus, bovine viral diarrhea virus, Epstein-Barr virus and the SARS coronavirus. ${ }^{36}$

Phytocomposites such as the sesquiterpene lactone artemisinin (2), used in antimalarial therapy, and other special metabolites with potential antiviral inhibitors such as steroids have become important allies in the search for treatment against the novel coronavirus. ${ }^{37-39}$

The flavonoids tomentin A-E (3-7) obtained from the fruits of Paulownia tomentosa inhibited SARS-CoV papain protease (PLpro), an important antiviral target due to its key roles in the SARS virus replication in a dose dependent with an $\mathrm{IC}_{50}$ between 5.0 and $14.4 \mu \mathrm{mol} \mathrm{L}{ }^{-1}{ }^{40}$ Thus, the identification of natural compounds with activity against essential SARS-CoV proteins is essential to validate the medicinal plant as a source of inhibitors of SARS-CoV PLpro.

The pathogenicity and deleterious effects of the novel coronavirus on the human biological system are still uncertain, however, one of the known effects is pulmonary fibrosis. ${ }^{41}$ This respiratory disease triggered by Covid-19 can be relieved using natural antioxidants such as polyphenols present in plants, since this pathology may be related to oxidative stress. ${ }^{42}$ Examples of antioxidant compounds are flavonoids, phenolic acids, tannins and ascorbic acid commonly found in citrus fruits.

The progression and severity of Covid-19 infection is exacerbated by the body's immune response through a phenomenon known as an "inflammatory storm". Thus, the use of low-toxicity natural anti-inflammatories can play an important role in this physiological effect. The Celastrol terpene, for example, is a metabolite with a broad spectrum of bioactivity in this type of pathology including anti-inflammatory. Even though, the use of immunosuppressant in the initial stage of the disease is not indicated, patients in critical condition develop extensive lung lesions that can lead to death. The anti-inflammatory action of Celastrol has been demonstrated in preclinical tests to reduce the levels of inflammatory cytokines, increase antioxidant defenses, show an in vitro immunomodulatory effect against the influenza $A$ virus and act against dengue viral infection. $^{43}$

Despite limited data about medicinal plants and their extracts and metabolites in directly inhibiting the SARS-CoV virus, many studies have focused on the curative potential of phytomedicines in the viral inhibition of other strains. These natural medicines can assist patients in relieving symptoms, shortening the hospitalization period and reducing the dosage of some drugs such as corticosteroids. ${ }^{44}$

In three months of the Covid-19 pandemic in China, hundreds of clinical trials were carried out using traditional Chinese medicine products to analyze the effectiveness of these products, for example Lian Hua Qing Wen and Tan Re Qing, in the form of injections, capsules or in association with other drugs in the treatment of infection..$^{45}$

Some plant species of widespread occurrence such as Glycyrrhiza glabra and Scutellaria baicalensis had their antiviral potential against coronavirus evidenced through in vitro tests, ${ }^{46}$ while others including Astragalus membranaceus and Echinacea purpurea can act in a preventive way assisting in the immune response acting as natural immunomodulators. ${ }^{47}$ Glycyrrhizin $(8)$, the main constituent of the roots of the antiviral species Glycyrrhiza glabra, demonstrated a significant effect on the inhibition of the viral replication of the SARS-CoV coronavirus $\left(\mathrm{EC}_{50}\right.$ of $\left.365 \mu \mathrm{mol} \mathrm{L^{-1 }}\right)$ as well as its derivatives. ${ }^{48}$ The medicinal herb Cassia tora was evaluated for anti-SARS-CoV activities using a cell-based assay that measured the cytopathogenic effect induced by SARS-CoV (CPE) in vitro on Vero E6 cells. Its extracts were considered potent inhibitors of SARS-CoV in concentrations between 25 and $200 \mu \mathrm{g} / \mathrm{mL}$. The resulting selective index values $\left(\mathrm{SI}=\mathrm{CC}_{50} / \mathrm{EC}_{50}\right)$ of the extracts of this plant were $>59.4 .{ }^{49}$ Cassia tora is a widely used medicinal herb with recognized pharmacological properties such as antimicrobial. Anthraquinones including emodin (9), physcion (10), and rhein (11) may be the active phytocompounds that confer these activities. ${ }^{50}$ Thus, we hypothesize that the active phytochemical components responsible for anti-SARS-CoV activity of Cassia tora may be contributed by emodin or other anthraquinone(s) suggested or known to be present in Cassia tora. ${ }^{49}$

Concerning isolated compounds, substances such as the polyphenol, cryptotanshinone (12) and the flavonoids kaempferol (13) and quercetin (14) have shown important antiviral properties against SARS-CoV acting on viral penetration and replication. ${ }^{33,45,51}$

The antiviral activity of phytocomposites may not always be related to inhibition of viral replication, but also in the interaction of the main viral proteins associated with virulence. For example, this mechanism occurs when the metabolites licorine (15) homoharringtonine (16), silvestrol (17), ouabain (18), tylofhorine (19) and 7-methoxycriptopleurine (20) are exposed to coronavirus. ${ }^{52}$ The secairidoide compounds and their glycosides from Gentiana scabra extract contributed to the anti-SARS activity detected. ${ }^{49}$

Many phytochemicals have been evaluated as promising therapeutic agents in the fight and prevention of the novel coronavirus. This is due to their antiviral action in apoptosis and RNA replication, synergistic effect with other synthetic or natural drugs, ability to 
modulate metabolic pathways, and act not only on syndromes caused by infection such as inflammation, but also the ability to prevent the attachment and internalization of the virus in many organs, including the liver, cardiovascular system and kidney. An example is the natural pigment curcumin (21). Curcumin acts on different molecular targets, which gives it the ability to change the structure of the virus surface protein, bind to receptors and block the entry of these receptors into the cell, inhibiting the ACE2 enzyme that SARS-CoV uses to enter the cell. In addition, curcumin has a positive effect in the treatment of pulmonary inflammation, edema, fibrosis and inhibiting oxidative stress responsible for serious lung injuries. ${ }^{53}$

Some vegetable small molecules present in food products such as the resveratrol (22) stilbene (23) found in red wine can act as a powerful antimicrobial agent. This compound showed significant viral inhibition of the expression of the protein used for replication of the MERS-CoV coronavirus, negatively regulated the apoptosis induced by the virus and prolonged cell survival even at reduced concentrations of the compound. ${ }^{54}$ Its effectiveness in viral inhibition of viruses that cause respiratory infections such as the Influenza virus has also been reported. ${ }^{55}$ The polyphenols tannic acid (24), theaflavin3-gallate (25) and theaflavin-3,3'-digallate (26) present in black tea also demonstrated an important inhibitory activity of the SARS-CoV

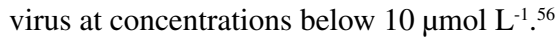

Other polyphenols, such as flavonoids, have been widely studied for their antiviral effect against species of CoVs due to their recognized antiviral property. Some findings have positively demonstrated that some flavonoids such as herbacetin (27), rhoifolin (28) and pectolinarin (29) are able to inhibit the enzymatic activity of the $3 \mathrm{C}$ protease enzyme (3CLpro) of the SARS-CoV coronavirus. ${ }^{57}$ Thus, flavonoids such as hesperidin (30), naringin (31), ECGC and quercetin (14) were selected for experiments against the novel coronavirus in order to determine the cytotoxicity of these compounds in the inhibition of the target protein RBD of nCoV-SP and ACE-2, whose theoretical study showed excellent pharmacokinetic properties, with good absorption, permeability, distribution, metabolism, minimal toxicity and good bioavailability. ${ }^{58}$ Other flavonoids such as flavones and biflavones extracted from the medicinal plant Torreya nucifera also showed inhibitory activity against the SARS-CoV virus. ${ }^{59}$ In addition, the flavonol myricetin (32) and flutone scutellarein (33) showed an inhibitory effect at nanomolar concentrations. ${ }^{60}$

Evaluation of the antiviral potential of 221 terpene and ligioid plant metabolites through cell proliferation and viral replication of the SARS-CoV virus demonstrated that ten diterpenoids, two sesquiterpenoids, two triterpenoids, five lignoids and the curcumin had effective viral inhibition potential. These phytocomposites showed high selectivity index and low toxicity for healthy cells, therefore, they are good candidates for further development as drugs in therapy against coronaviruses. ${ }^{61}$

Regarding the antiviral activity of alkaloids against coronavirus, some findings demonstrated the antiviral potential of the alkaloids tetrandrine (34), fangchinoline (35) and cefarantine (36), which inhibited cell death induced by early stage in less than $1 \mu \mathrm{M}$ against human lung cells MRC-5 infected with HCoV-OC43. ${ }^{62}$

In addition to the epidemiological aspects of COVID-19 and the nature of the SARS-CoV-2 virus, there is the need for researching into new antiviral agents or alternative treatment agents. We discuss and summarize possible candidates for antiviral agents focusing on phytochemicals known as agile and objective strategy to lead to pharmaceutical development.

Figure 2 describes the molecular structures of all molecules of natural origin described in this review. This arsenal of phytochemicals shows promising candidates for therapeutic application against COVID-19 and the possibility of exploring these molecules as auxiliary therapies to fight infection and pathologies related to SARS-CoV-2 infection.

From the bibliographic research carried out in this review and discussed in the text, some phytochemicals and their respective classes of secondary metabolites (flavonoids, alkaloids, coumarin, tannins, saponin and steroid) with exclusive anti-SARS-CoV activity $\left(\mathrm{IC}_{50}\right.$ in $\mu \mathrm{mol} \mathrm{L} \mathrm{L}^{-1}$ ) were extracted. The most significant results are described in Table 1.

\section{CONCLUSIONS}

Despite the progress made in screening drugs with anti-SARSCoV-2 properties and in the searching for immunization through vaccines and the challenges arising from the generation of mutant viral strains, the whole world continues to suffer from the consequences

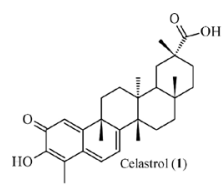

Clastrol(1)

$\begin{array}{lll}\text { Tomentin } \mathrm{A}(3) \mathrm{R} 1-\mathrm{OH}, & \mathrm{R} 2-\mathrm{OH}, \quad \mathrm{R} 3-\mathrm{H}, & \mathrm{R} 4-\mathrm{H} \\ \text { Tomentin } \mathrm{B}(4) \mathrm{R} 1=\mathrm{OH}, & \mathrm{R} 2-\mathrm{OCH}_{3}, \mathrm{R} 3-\mathrm{H}, & \mathrm{R} 4-\mathrm{H}\end{array}$

$\begin{array}{ll}\text { Tomentin } \mathrm{B}(\boldsymbol{4}) \mathrm{R} 1=\mathrm{OH}, \quad \mathrm{R} 2-\mathrm{OCH}_{3}, \mathrm{R} 3-\mathrm{H}, & \mathrm{R} 4-\mathrm{H} \\ \text { Tomentin } \mathrm{C}(\mathbf{5}) \mathrm{R} 1=\mathrm{OCH}_{3}, \mathrm{R} 2=\mathrm{OCH}_{3}, \mathrm{R} 3=\mathrm{OH}, & \mathrm{R} 4=\mathrm{H}\end{array}$ Tomentin $\mathrm{D}(\mathrm{G}) \mathrm{Rl}=\mathrm{OCH}_{3}, \mathrm{R} 2=\mathrm{OCCH}_{3}, \mathrm{R} 3=\mathrm{OCH} \mathrm{H}_{3}, \mathrm{R} 4=\mathrm{H}$ Tomentin $\mathrm{E}(7) \mathrm{R} 1=\mathrm{OCH}_{3}, \quad \mathrm{R} 2=\mathrm{OH}, \quad \mathrm{R3}=\mathrm{H}, \quad \mathrm{R} 4=\mathrm{OH}$

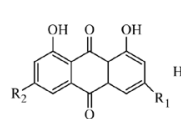

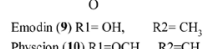
Physcion (19) $\mathrm{Rl}=\mathrm{OCH}_{3}, \quad \mathrm{R} 2-\mathrm{CH}$
Rhein (11) $\mathrm{Rl}=\mathrm{COOH}, \quad \mathrm{R} 2=\mathrm{H}$$$
0
$$$$
\text { Licorine (15) }
$$

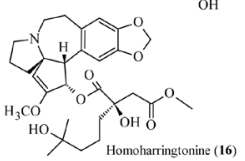

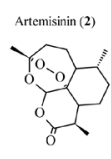
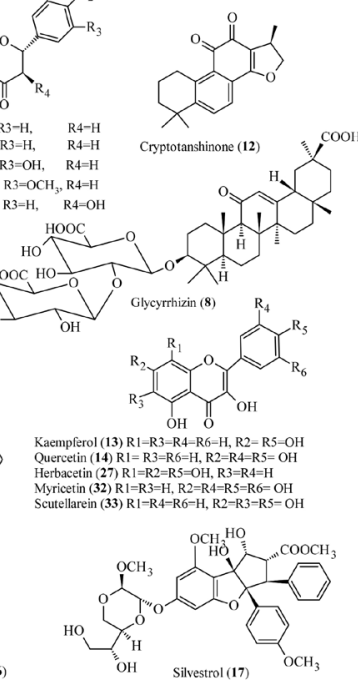
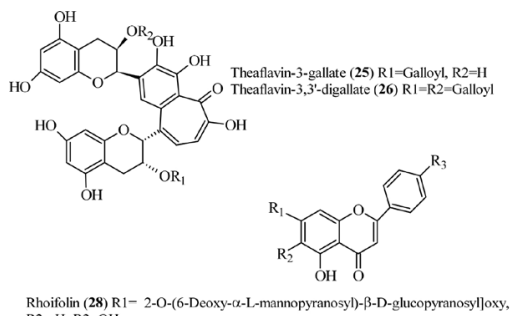

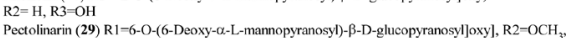
$\mathrm{R} 3=\mathrm{OCH}_{3}$

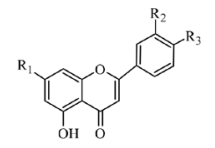

Hesperidin (30) $\mathrm{R} 1=6-\mathrm{O}-\alpha-\mathrm{L}-\mathrm{thamnos} \mathrm{l}-\mathrm{D}-\mathrm{d}$ lucoside, $\mathrm{R} 2=\mathrm{OH}, \mathrm{R} 3=\mathrm{OCH}$ (aning
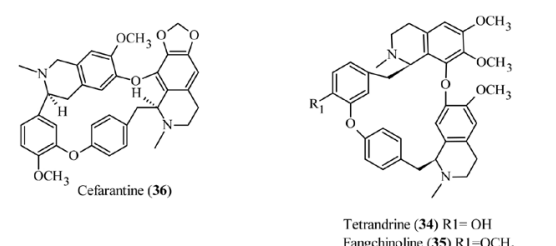

Figure 2. Chemical structures of secondary metabolites as potential natural products for therapeutic application against COVID-19 
Table 1. Anti-SARS-CoV antiviral activity of phytochemical small molecules against human coronavirus strains

\begin{tabular}{|c|c|c|c|}
\hline Compound class & Compound name & $\mathrm{EC}_{50}$ or $\mathrm{IC}_{50}\left(\mu \mathrm{mol} \mathrm{L}{ }^{-1}\right)$ & Reference \\
\hline Coumarin & Leptodactylone & $\sim 450$ & Yang et al. ${ }^{63}$ \\
\hline Alkaloid & Lycorine & $34.5-39.2$ & Li et al. ${ }^{64}$ \\
\hline Flavonoid & Luteolin & 10.6 & Yi et al..$^{65}$ \\
\hline Tannin & Tetra- $O$-galloyl- $\beta$-D-glucose & 4.5 & Yi et al..$^{65}$ \\
\hline Saponin & Glycyrrhizin & $365 \pm 12$ & Hoever et al. ${ }^{66}$ \\
\hline Flavonoid & Myricetin & $2.71 \pm 0.19$ & Yu et al..$^{60}$ \\
\hline Steroid & $\beta$-sitosterol & 115 & Luo et al. ${ }^{67}$ \\
\hline Flavonoid & Tomentin A & $6.2 \pm 0.04$ & Cho et al. ${ }^{40}$ \\
\hline
\end{tabular}

from the novel coronavirus pandemic. Although, there are hundreds of clinical trials in advanced stages, there is no measure to combat and control the pandemic other than health care and isolation. Due to the unavailability of approved treatment regimen to treat infected individuals and vaccines to immunize people especially at high risk including the elderly and persons with chronic diseases, there is a global search for the discovery of antiviral candidates capable of treating the infection caused by SARS-CoV-2. Many controlled and randomized clinical studies of existing drugs, used in treating other diseases, are ongoing in a quest to discover a cure for COVID-19. However, none of them have shown proven efficacy against the novel coronavirus. Thus, the quick identification of new antivirals as well as safe prophylactic approaches is of fundamental importance and natural products stand out as a promising source for such discoveries. This work becomes of extreme importance and emerging disclosure, as it shows medicinal plants that can assist in Covid-19 antiviral therapy and possible candidates for exploration as potential anticoronavirus viral inhibitor drugs as well as assist in the prevention of side effects of the drugs used, since in China, a significant portion of patients infected with SARS-CoV-2 made use of traditional Chinese medicine to treat COVID-19. ${ }^{45}$ It is noteworthy that more clinical tests still need to be carried out to guarantee the use and effectiveness of the medicinal plants highlighted in this review. An important aspect to consider is that the medicinal plants and compounds discussed here already have some established pharmacological effects and can be valuable candidates for safe and effective antiviral agents in the fight and control of COVID-19.

\section{ACKNOWLEDGMENT}

Brazilian Research Agencies CNPq, FAPEMIG, INCTBio and CAPES for financial support.

\section{REFERENCES}

1. Al Hasan, S. M.; Saulam, J.; Kanda, K.; Hirao, T.; Bull. W. H. O. 2020 , $17,1$.

2. Wang, J.; Zand, M. S.; OSF Preprints, no prelo.

3. WHO 2021, available at https://covid19.who.int/, accessed on February 2021.

4. Ren, L. L.; Wang, Y. M.; Wu, Z. Q.; Xiang, Z. C.; Guo, L.; Xu, T.; Jiang, Y.-Z.; Xiong, Y.; Liu, Y.-J.; Li, X.-W.; Li, H.; Fan, G.-H.; Gu, X.-Y.; Xiao, Y.; Gao, H.; Xu, J-Y.; Yang, F.; Wang, X.-M.; Wu, C.; Chen, L.; Liu, Y. W.; Liu, B.; Yang, J.; Wang, X.-R.; Dong, X.; Li, L.; Huang, C.L.; Zhao, J.-P.; Hu, Y.; Cheng, Z.-S.; Liu, L.-L.; Qian, Z.-H.; Qin, C.; Jin, Q.; Cao, B.; Wang, J. W.; Chin. Med. J. 2020, 133, 1015.

5. Maganga, D.; Pinto, A.; Mombo, I. M.; Madjitobaye, M.; Beyeme, A. M. M.; Boundenga, L.; Gouilh, Mar.; N'Dilimabaka, N.; Drexler, J. F.; Drosten, C.; Leroy, E. M.; Sci. Rep. 2020, 10, 7314.
6. De Sabato, L.; Lelli, D.; Faccin, F.; Canziani, S.; Di Bartolo, I.; Vaccari, G.; Virus Res. 2019, 260, 60.

7. Guan, W. J.; Ni, Z. Y.; Hu, Y.; Liang, W. H.; Ou, C. Q.; He, J. X.; N. Engl. J. Med. 2020, 382, 1708.

8. WHO 2020a, available at https://www.who.int/emergencies/diseases/ novel-coronavirus-2019, accessed at February 2021.

9. Mahase, E.; BMJ. 2020, 368, 265.

10. McKee, D. L.; Sternberg, A.; Stange, U.; Laufer, S.; Naujokat, C.; Pharmacol. Res. 2020, 104859.

11. Van der Hoek, L.; Antivir. Ther. 2007, 12, 651.

12. Geller, C.; Varbanov, M.; Duval, R. E.; Viruses 2012, 4, 3044.

13. Trindade, G. G.; Caxito, S.; Xavier, A. R. E.; Xavier, M. A.; Brandão, F.; An. Acad. Bras. Cienc. 2020, 92, e20200466.

14. Zhu, N.; Zhang, D.; Wang, W.; Li, X.; Yang, B.; Song, J.; Niu, P.; N. Engl. J. Med. 2020, 382, 727.

15. Báez-Santos, Y. M.; ST John, S. E.; Mesecar, A. D.; Antiviral Res. 2015, 115, 21.

16. Zhou, P.; Yang, X. L.; Wang, X. G.; Hu, B.; Zhang, L.; Zhang, W.; Chen, H. D.; Nature 2020, 579, 270.

17. Ashburn, T. T.; Thor, K. B.; Nat. Rev. Drug Discov. 2004, 3, 673.

18. Ison, M. G.; Clinics in Chest Medicine 2017, 38, 139.

19. Assis, L.; de Castro, A. A.; de Jesus, J. P. A.; Ramalho, T.; La Porta, F. ChemRxiv, in press.

20. Eastman, R. T.; Roth, J. S.; Brimacombe, K. R.; Simeonov, A.; Shen, M.; Patnaik, S.; Hall, M. D.; ACS Cent. Sci. 2020, 6, 672.

21. Ornstein, M. H.; Sperber, K.; Arthritis Rheumatol. 1996, $39,157$.

22. de Castro, A. A.; Assis, L. C.; Ramalho, T. C.; La Porta, F. A.; Research Square, in press.

23. Ben-Zvi, I.; Kivity, S.; Langevitz, P.; Shoenfeld, Y.; Clin. Rev. Allergy Immunol. 2012, 42, 145.

24. Wellems, T. E.; Plowe, C. V.; J. Infect. Dis. 2001, 184, 770.

25. Madrid, P. B.; Panchal, R. G.; Warren, T. K.; Shurtleff, A. C.; Endsley, A. N.; Green, C. E.; Bavari, S.; ACS Infect. Dis. 2015, 1, 317.

26. Retallack, H.; Di Lullo, E.; Arias, C.; Knopp, K. A.; Laurie, M. T.; Sandoval-Espinosa, C.; Pollen, A. A.; Proc. Natl. Acad. Sci. U. S. A. 2016, 113, 14408

27. Rossignol, J-F.; J. Infect. Public Health. 2016, 9, 227.

28. Wang, M.; Cao, R.; Zhang, L.; Yang, X.; Liu, J.; Xu, M.; Shi, Z.; Hu, Z.; Zhong, W.; Xiao, G.; Cell Res. 2020, 30, 269.

29. WHO 2020b, available at https://apps.who.int/iris/handle/10665/330893, accessed at February 2021.

30. Ren, R.; Mao, Y.; Ruan, Z.; Wang, Y.; Zhang, Y.; Du, J.; Yu, W.; Int. J. Clin. Exp. Pathol. 2017, 10, 9302

31. Ling, C. Q.; J. Integr. Med. 2020, 18, 87.

32. WHO 2004, available at https://apps.who.int/iris/handle/10665/43029, accessed at February 2021.

33. Zhang, D-H.; Wu, K-1.; Zhang, X.; Deng, S-Q.; Peng, B.; J. Integr. Med. 2020, $18,152$.

34. Lin, L. T.; Hsu, W. C.; Lin, C. C.; J. Trad. Complement. Med. 2014, 4, 24. 
35. Wang, S.-X.; Wang, Y.; Lu, Y.-B.; Li, J.-Y.; Song, Y.-J.; Nyamgerelt, M.; Wang, X.-X.; J. Integr. Med. 2020, 18, 275.

36. Haq, F. U.; Roman, M.; Ahmad, K.; Rahman, S. U.; Ali Shah Dr. S. M.; Suleman, N.; Ullah, S.; Ahmad, I.; Ullah, W.; Phytother. Res. 2020, 34, 2423.

37. Efferth, T.; Romero, M. R.; Wolf, D. G.; Stamminger, T.; Marin, J. J.; Marschall, M.; Clin. Infect. Dis. 2008, 47, 804.

38. Karamoddini, M. K.; Emami, S. A.; Ghannad, M. S.; Sani, E. A.; Sahebkar, A.; Asian Biomed. 2011, 5, 63.

39. Khan, M. A. A.; Jain, D. C.; Bhakuni, R. S.; Zaim, M.; Thakur, R. S.; Plant. Sci. 1991, 75, 161.

40. Cho, J. K.; Curtis-Long, M. J.; Lee, K. H.; Kim, D. W.; Ryu, H. W.; Yuk, H. J.; Park, K. H.; Bioorg. Med. Chem. 2013, 21, 3051.

41. Conti, P.; Gallenga, C. E.; Tetè, G.; Caraffa, A.; Ronconi, G.; Younes, A.; Kritas, S. K.; Journal of Biological Regulators \& Homeostatic Agents 2020, 34, 333.

42. Day, B. J.; Antioxid. Redox Sign. 2008, 10, 355.

43. Habtemariam, S.; Nabavi, S. F.; BerindanNeagoe, I.; Cismaru, C. A.; Izadi, M.; Sureda, A.; Nabavi. S. M.; Phytother. Res. 2020, 34, 1189.

44. Liu, X.; Zhang, M.; He, L.; Li, Y.; Cochrane Database of Systematic Reviews 2012, 10, CD004882.

45. Yang, Y.; Islam, M. S.; Wang, J.; Li, Y.; Chen, X.; Int. J. Biol. Sci. 2020, 16, 1708.

46. Chen, F.; Chan, K. H.; Jiang, Y.; Kao, R. Y. T.; Lu, H. T.; Fan, K. W.; Guan, Y.; J. Clin. Virol. 2004, 31, 69.

47. Block, K. I.; Mead, M. N.; Integr. Cancer Ther. 2003, 2, 247.

48. Cinatl, J.; Morgenstern, B.; Bauer, G.; Chandra, P.; Rabenau, H.; Doerr, H. W.; Lancet 2003, 361, 2045.

49. Wen, C. C.; Shyur, L-F.; Jan, J-T.; Liang, P-H.; Kuo, C-J.; Arulselvan, P.; Wu, J-B.; Kuo, S-C.; Yang, N-S.; J. Trad. Complement. Med. 2011, $1,41$.

50. Kim, Y. M.; Lee, C. H.; Kim, H. G.; Lee, H. S.; J. Agric. Food Chem. 2004, 52, 6096.

51. Michaelis, M.; Doerr, H. W.; Cinatl Jr., J.; Phytomedicine 2011, 18, 384.

52. Islam, M. T.; Sarkar, C.; El-Kersh, D. M.; Jamaddar, S.; Uddin, S. J.; Shilpi, J. A.; Mubarak, M. S.; Phytother. Res. 2020, 34, 2471.
53. Zahedipour, F.; Hosseini, S.; Sathyapalan, A. T.; Majeed, M.; Jamialahmadi, T.; Al-Rasadi, K.; Banach, M.; Sahebkar, A.; Phytother. Res. 2020, 34, 2911.

54. Lin, S. C.; Ho, C. T.; Chuo, W. H.; Li, S.; Wang, T. T.; Lin, C. C.; BMC Infect. Dis. 2017, 17, 144.

55. Lin, C. J.; Lin, H. J.; Chen, T. H.; Hsu, Y. A.; Liu, C. S.; Hwang, G. Y.; Wan, L.; PLoS One 2015, 10, e0117602.

56. Chen, C. N.; Lin, C. P.; Huang, K. K.; Chen, W. C.; Hsieh, H. P.; Liang, P. H.; Hsu, J. T. A.; Evid. Based Complement. Alternat. Med. 2005, 2 , 209.

57. Jo, S.; Kim, S.; Shin, D. H.; Kim, M. S.; J. Enzyme Inhib. Med. Chem. 2020, 35, 145.

58. Bhowmik, D.; Nandi, R.; Kumar, D.; ChemRixv, in press.

59. Ryu, Y. B.; Jeong, H. J.; Kim, J. H.; Kim, Y. M.; Park, J. Y.; Kim, D.; Rho, M. C.; Bioorg. Med. Chem. 2010, 18, 7940.

60. Yu, M. S.; Lee, J.; Lee, J. M.; Kim, Y.; Chin, Y. W.; Jee, J. G.; Jeong, Y. J.; Bioorg. Med. Chem. Lett. 2012, 22, 4049.

61. Wen, C. C.; Kuo, Y. H.; Jan, J. T.; Liang, P. H.; Wang, S. Y.; Liu, H. G.; Hou, C. C.; J. Med. Chem. 2007, 50, 4087.

62. Kim, D. E.; Min, J. S.; Jang, M. S.; Lee, J. Y.; Shin, Y. S.; Park, C. M.; Kwon, S.; Biomolecules 2019, 9, 696.

63. Yang, Q. Y.; Tian, X. Y.; Fang, W. S.; J. Asian Nat. Prod. Res. 2007, 9, 59.

64. Li, S. Y.; Chen, C.; Zhang, H. Q.; Guo, H. Y.; Wang, H.; Wang, L.; Zhang, X.; Hua, S. N.; Yu, J.; Xiao, P. G.; Li, R. S.; Tan, X.; Antiviral Res. 2005, 67, 18.

65. L. Yi, Z. Li, K. Yuan, X. Qu, J. Chen, G. Wang, G.; Zhang, H.; Luo, H.; Zhu, L.; Jiang, P.; Chen, L.; Shen, Y.; Luo, M.; Zuo, G.; Hu, J.; Duan, D.; Nie, Y.; Shi, X.; Wang, W.; Han, Y.; Li, T.; Liu, Y.; Ding, M.; Deng, H.; Xu, X.; J. Virol. 2004, 78, 11334.

66. Hoever, L.; Baltina, M.; Michaelis, R.; Kondratenko, L.; Baltina, G. A.; Tolstikov, G. A.; Doerr, H. W.; Cinatl, J.; J. Med. Chem. 2005. 48, 1256.

67. Luo, W.; Su, X.; Gong, S.; Qin, Y.; Liu, W.; Li, J.; Yu, H.; Xu, Q.; Biosci. Trends 2009, 3, 124. 